\title{
VIBRATION ASSISTED DEEP HOLE MICRO-DRILLING: A Preliminary Experimental StUdy
}

\author{
Todić Rajko, Bartulović Ante
}
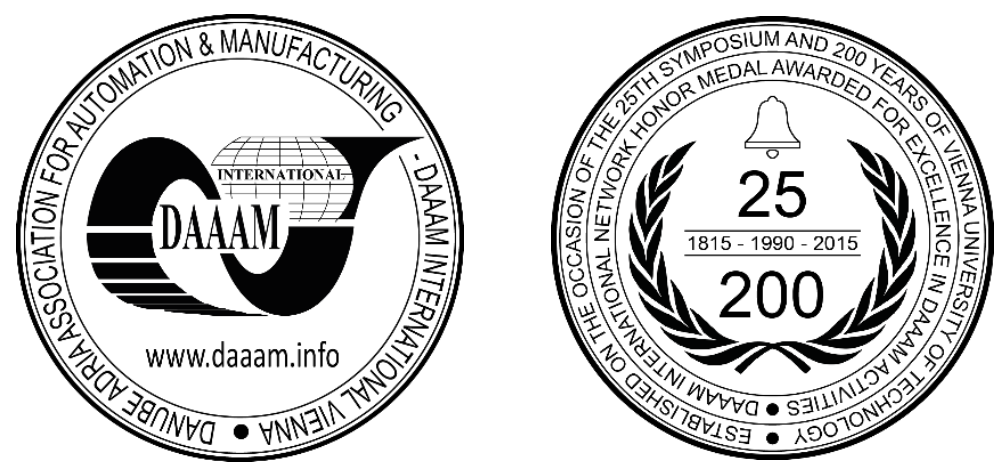

This Publication has to be referred as: Todic, R[ajko] \& Bartulovic, A[nte] (2016). Vibration Assisted Deep Hole Micro-Drilling: a Preliminary Experimental Study, Proceedings of the 27th DAAAM International Symposium, pp.08220826, B. Katalinic (Ed.), Published by DAAAM International, ISBN 978-3-902734-08-2, ISSN 1726-9679, Vienna, Austria

DOI: $10.2507 / 27$ th.daaam.proceedings.119

\begin{abstract}
The process of deep hole micro-drilling is characterized with a higher depth to diameter ratio that leads to difficult evacuation of the chip from the hole and increased friction between the tool and the workpiece. This causes an increase of drill wear, drilling forces and torque. In combination with the small stiffness of the drill could often lead to the tool breakage, less productivity and sometimes to the loss of the workpiece. One option to increase the reliability of the process is superimposing vibrations to the standard kinematics of the drilling process. Preliminary experimental investigations on vibration assisted deep-hole micro-drilling of AlMg3 material, with hole aspect ratio of 1:20, are performed. Drill lifetime related with drill breakage is compared between vibration assisted and conventional micro drilling process.
\end{abstract}

Keywords: Micro-drilling; Deep hole drilling; Vibration assisted drilling, Drill breakage; Tool lifetime

\section{Introduction}

The increase of production of devices with micro features, mainly in medical equipment, electronic and optical devices, automotive parts, etc., demands efficient and reliable technologies of micro machining. Mechanical microdrilling is one of the methods for producing micro holes among other modern technologies like electrical discharge machining, ultrasound machining, laser machining and electro-chemical machining. Advantages of using mechanical micro-drilling are process independence from workpiece material properties, reduced thermal deformations, acceptable material removal rates with satisfying shape and surface quality, less requirements for the final machining, etc. Deep hole mechanical micro-drilling produces micro-holes with a diameter less than $1 \mathrm{~mm}$ with the bigger hole aspect ratio (depth/diameter) more than 15. The main problems related with deep micro-drilling are low rigidity of the drill, difficult chip extraction and difficult lubrication supply to the deep micro hole due to big hole aspect ratio. This could often lead to the tool breakage, less productivity and sometimes to the loss of the workpiece. The application of vibrations at the micro-drilling, especially for deep holes, presents a possible progress in solving those issues to increase the reliability of micro drilling processes. 


\section{Micro drilling and vibration assisted drilling}

Vibration assisted drilling occurs when the vibrations are superimposed to the standard kinematics of the drilling process in the drill axis direction or torsional, on the side of the drill or of the workpiece. Vibrations can vary from frequencies of $100 \mathrm{~Hz}$ to ultrasonic vibrations (more than $20 \mathrm{kHz}$ ). Vibrations are changing the mechanism of formation of the chip, a thinner and smaller chip is created, which reduces friction between the chip and the drill, as well as between the chip and the workpiece hole. The thinner chip can easily evacuate from the hole, thus reducing the forces acting on the drill bit. Cutting mechanism is shown on the Fig. 1, where the tool vibrates with displacement $x$, vibration amplitude $A$, angular frequency $\omega$, tool vibration speed $v_{t}$ and cuts workpiece in period $t_{c}$.

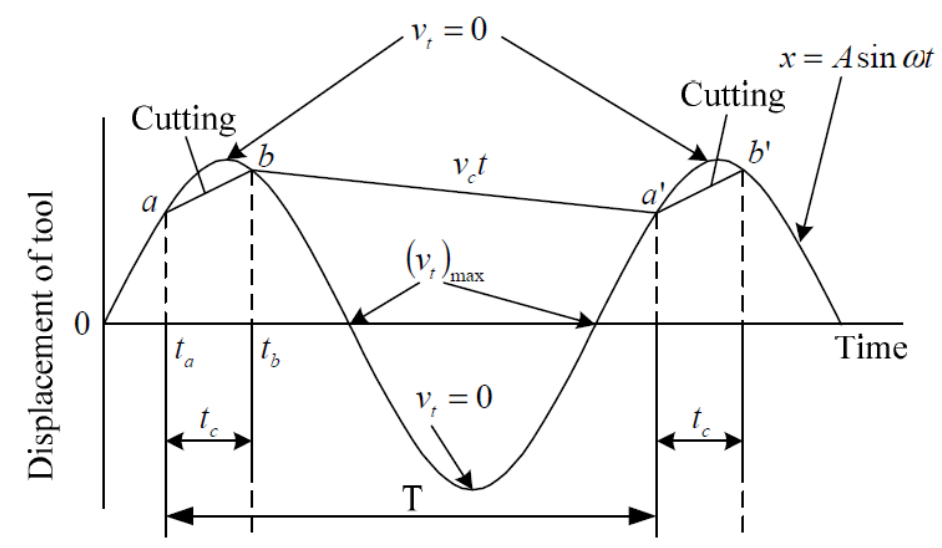

Fig. 1. Vibration cutting state in vibration assisted drilling

If $A \omega>v_{c}$ tool will separate from the workpiece and the condition for the vibration cutting is satisfied, otherwise it stays a conventional cutting process. The relationship of contact time between tool and workpiece $r=t_{c} / T$ has been introduced [1]. For vibration assisted cutting $r$ should be as low as possible, which can be achieved either with increasing the frequency and amplitude of vibration or with lowering the cutting speed $v_{c}$.

The results of the application of vibration assisted drilling with conventional drilling show many positive effects such as reduced cutting forces and wear, longer tool lifetime and better surface quality, improved geometry and dimensions of the hole, better surface quality of the bore, smaller burr formation, etc. Evidence of the benefits of vibration in drilling were mainly focused on ultrasonic vibration assisted drilling of relatively large diameters or small depth vibration assisted micro drilling. Most of them were based on experimental results, selectively taking into account, in various combinations, characteristics like force of drilling process, chip characteristics, drill lifetime, material removal rate, quality of the hole and burr forming.

One main advantage of vibration for larger diameter drilling is the reduction of forces and moments acting on the drill bit. Reduction of forces and moments acting on the drill bit with vibration assistance is documented during drilling of various types of materials like aluminum [2], copper [3], nickel [4] and titanium [5] alloys, as well as cortical bone [6] and composite materials like carbon fiber-reinforced plastics [7]. Vibration assistance provides a mechanism to create shorter chip and their better extraction from the hole [8], thus avoiding the need for periodic drill retracting. Reduction of chip size is listed as one of the main reasons for the increase drills in life expectancy [9]. Vibration assisted micro-drilling investigations show significantly lower level of drilling force [10], longer drill lifetime [11] and smaller chip size [12].

Vibration assisted deep hole micro-drilling, after review of available literature, has not been sufficiently investigated, there is no sufficient number of experimental nor theoretical models of the process, which is understandable due to the unconventional mechanisms of cutting and complexity of the problem. There are many challenges facing the use of vibrations in the drilling: additional equipment or machine modifications, vibration drilling control systems are relatively undeveloped, vibration parameters depend on the application or require adjustment during drilling. This article presents preliminary experimental analysis of influence of vibration application on the drill breakage related with drill lifetime and productivity in the deep hole micro-drilling process. This is a part of experimental investigations with aim to establish a model of vibration assisted deep hole micro-drilling as an important step to the realization in industrial applications.

\section{Experiment}

The experimental setup developed in HSTec consists of the following components (Fig. 2):

- Motor spindle

- Z-axis dynamic linear motor

- Vibration generator

- Force sensors

- Control computer / data base 


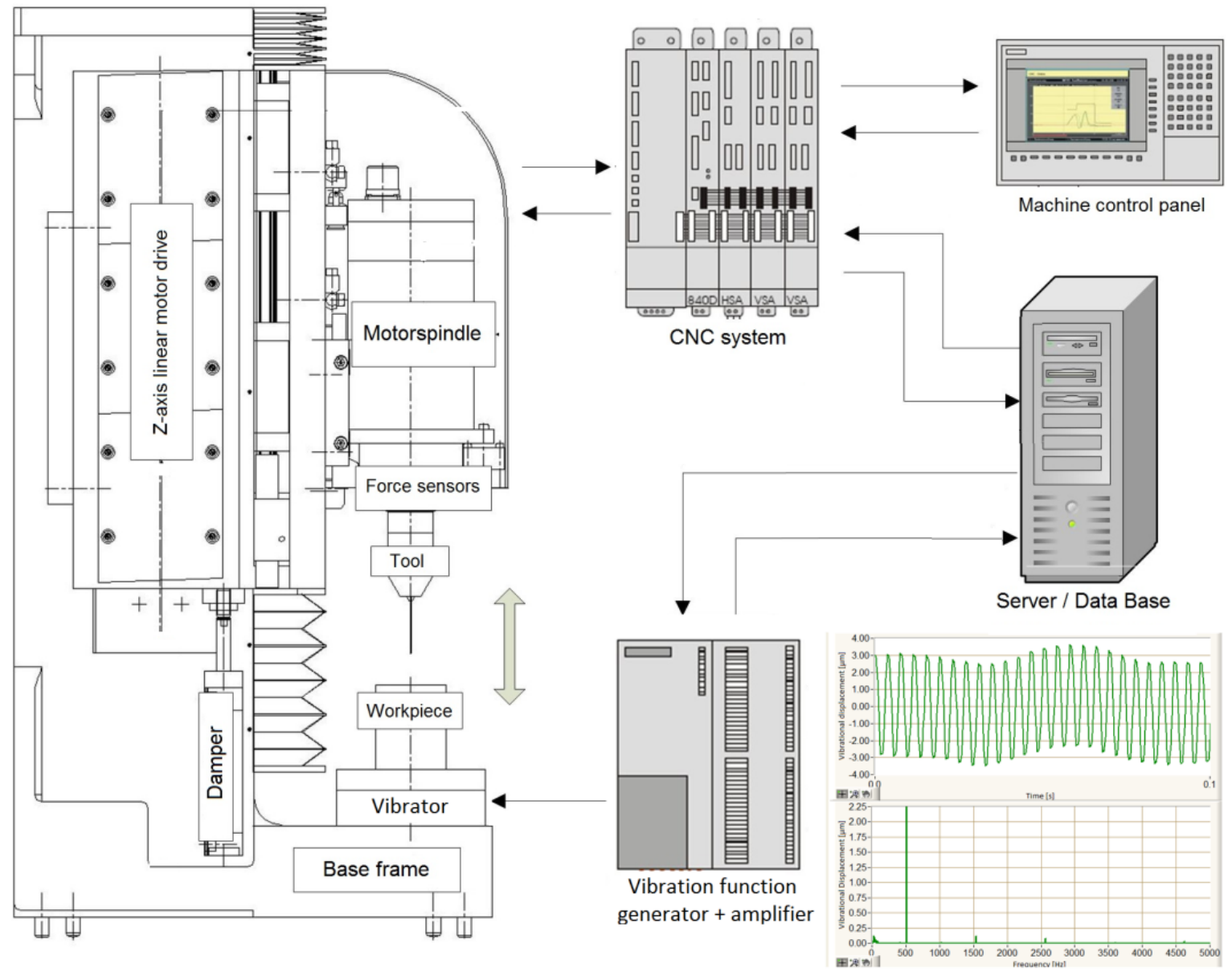

Fig. 2. Schematic diagram of drilling experimental setup

The drilling machine has a 2-pole asynchronous motor with rated power of 4,9 kW and rated speed of 39.400 min-1 installed. It has a manual clamping system and is equipped with HSK 32 tool interface. Highly dynamic vertical axis is performed by use of a permanent, magnet-triggered, synchronous linear motor with rated thrust of $625 \mathrm{~N}$. A pneumatic cylinder is installed in the Z-axis for balancing and damping purposes.
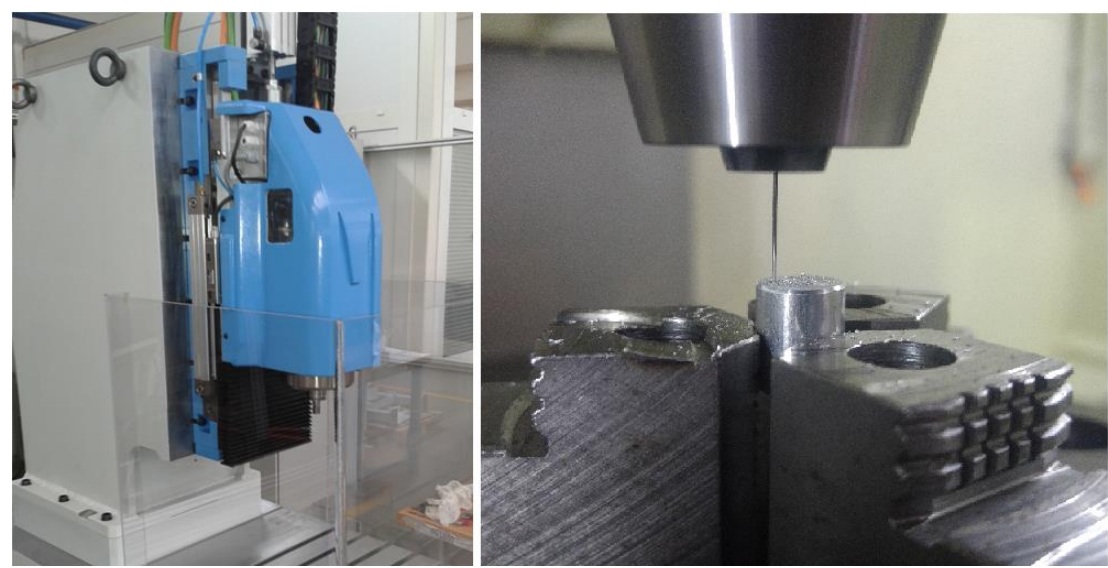

Fig. 3. Conventional micro drilling tests on the micro-drilling machine

The system for generating vibrations is installed below the clamping device, so the vibrations are generated on the side of the workpiece. Electromagnetic vibration generator [Fig. 4] can create vibration frequencies up to $3 \mathrm{kHz}$, but vibration frequency and amplitude are inversely proportional, which means that with higher frequency generator forms smaller amplitudes. Besides this limitation, magnetic fields created in the generator make an influence on the chip extraction during machining of steel and that was the reason that nonmagnetic material as aluminum was used for this stage of investigation. 

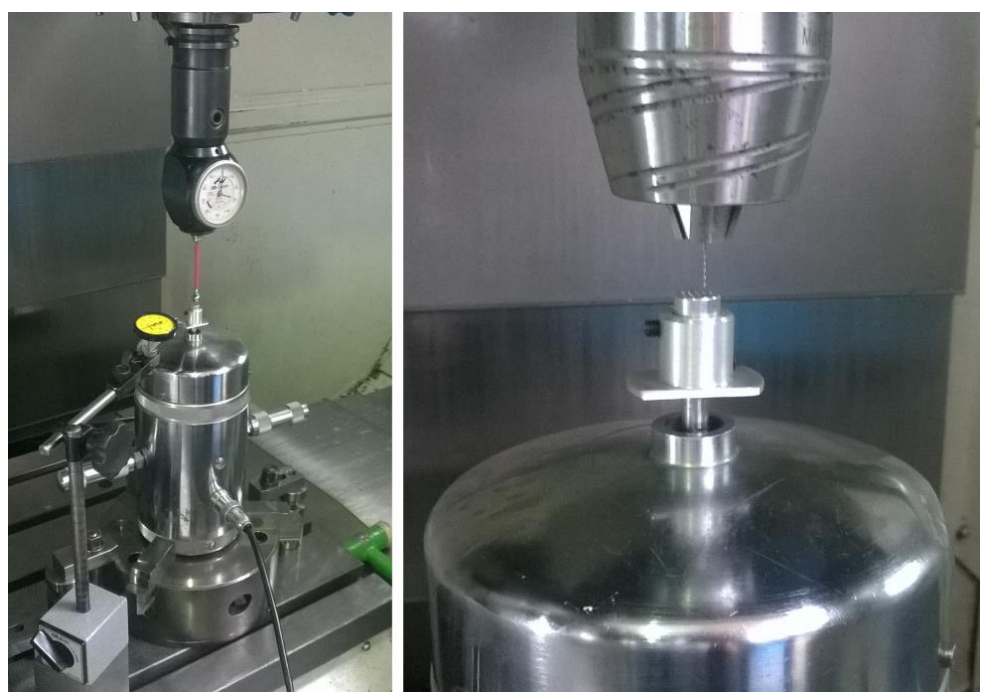

Fig. 4. Vibration assisted micro-drilling tests with vibration generator

Deep micro drilling experiments are performed with conventional spiral solid carbide drills Gühring 706 HVM with diameter of $0.5 \mathrm{~mm}$, depth of holes $10 \mathrm{~mm}$, with and without the application of vibration, in order to define the impact of the application of vibration to the deep micro drilling. Drilling and vibration parameters are presented in Table 1.

\begin{tabular}{|c|c|c|c|c|c|}
\hline \multirow{2}{*}{$\begin{array}{l}\text { Experimental } \\
\text { Setup No. }\end{array}$} & \multirow{2}{*}{$\begin{array}{c}\text { Rotational } \\
\text { speed } \\
(\text { rpm })\end{array}$} & \multirow{2}{*}{$\begin{array}{l}\text { Feed rate } \\
(\mathrm{mm} / \mathrm{rev})\end{array}$} & \multirow{2}{*}{$\begin{array}{c}\text { Peck } \\
\text { drilling } \\
\text { feed }(m m)\end{array}$} & \multicolumn{2}{|c|}{ Vibration assist. drilling } \\
\hline & & & & $\begin{array}{c}\text { Frequency } \\
(H z)\end{array}$ & $\begin{array}{c}\text { Amplitude } \\
(\mu m)\end{array}$ \\
\hline Setup 1 & 15.000 & 0,008 & 0,15 & \multicolumn{2}{|c|}{ no vibrations } \\
\hline Setup 2 & 15.000 & 0,008 & 0,15 & 250 & 4,5 \\
\hline Setup 3 & 15.000 & 0,07 & 0,15 & 250 & 4,5 \\
\hline
\end{tabular}

Table 1. Drilling parameters and vibration parameters

\section{Results}

The results shows that the vibration assistance has extremely positive impact on a micro-drill lifetime. It can be concluded that vibration assisted micro-drilling (Setup 2) prolongs drill lifetime in comparison with conventional microdrilling (Setup 1), when using the same parameters. It proved that the use of the vibration assistance on the deep hole micro drilling has a similar effect on the lifetime as documented in the literature for the vibration assisted drilling with larger diameter drills and for smaller depth holes micro-drilling.
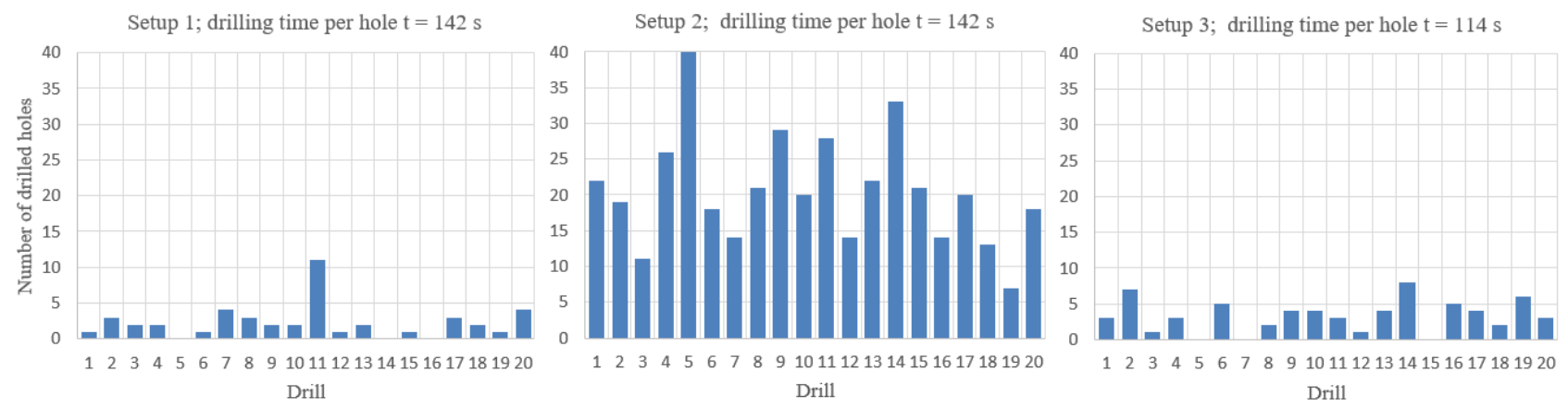

Fig. 5. Number of drilled holes related to the setup type

Another comparison shows that approximately the same number of drilled holes can be achieved when using vibration assisted micro-drilling with almost nine times higher feed rate (Setup 3) than the conventional micro-drilling (Setup 1). That enables shorter drilling time and higher productivity. Shorter and thinner chip is produced with the vibration assisted process [Fig 6] with the assumption that it leads to less chip clogging in the hole and to reducing of cutting forces. Reduced load on the micro-drill, which is characterized with small rigidity, could be a reason for higher drill durability. 

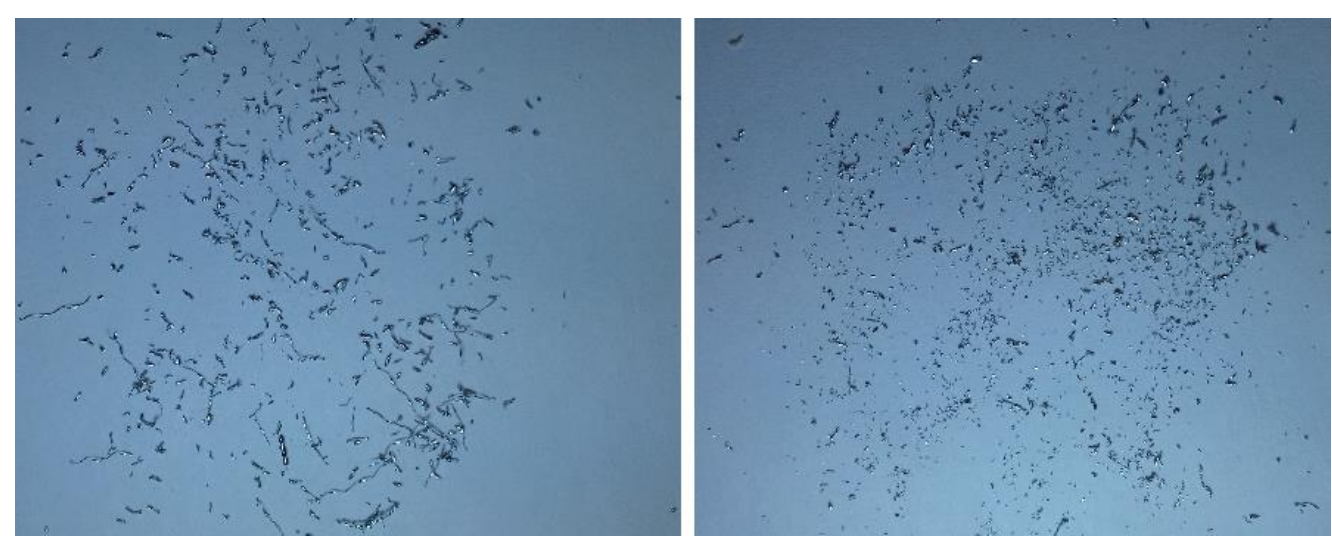

Fig. 6. Chip from conventional (left) and vibration assisted (right) deep hole micro-drilling

\section{Conclusion and future work}

Preliminary experimental study showed advantages of using vibration assistance which led to thinner and smaller chip which enabled bigger number of drilled holes per drill with the same drilling parameters. Another advantage is possibility of using increased feed which leads to shorter drilling time and higher productivity. In the future work emphasis will be placed on the analysis of the impact of drilling and vibration parameters, in order to better define the rules necessary for the development of this hybrid process. Development of a of deep micro-vibration assisted drilling model could allow selection of drilling parameters (speed, feed or retraction of the drill) and vibration parameters (frequency and amplitude), related with the characteristics of the workpiece material and dimensions of the hole. The assumption is that implementing selection of process parameters will prevent tool breakage, reduce wear and prolong the life of the drill, with the potential to improve the quality holes. The developed model could be used in the development of the adaptive control of vibration assisted micro drilling processes.

\section{References}

[1] Nath, C., \& Rahman, M. (2008). Effect of machining parameters in ultrasonic vibration cutting. International Journal of Machine Tools and Manufacture,48(9), 965-974.

[2] Chang, S. S., \& Bone, G. M. (2009). Thrust force model for vibration-assisted drilling of aluminum 6061T6. International Journal of Machine Tools and Manufacture, 49(14), 1070-1076.

[3] Azarhoushang, B., \& Akbari, J. (2007). Ultrasonic-assisted drilling of Inconel 738-LC. International Journal of Machine Tools and Manufacture, 47(7), 1027-1033.

[4] Heisel, U., Wallaschek, J., Eisseler, R., \& Potthast, C. (2008). Ultrasonic deep hole drilling in electrolytic copper ECu 57. CIRP Annals-Manufacturing Technology, 57(1), 53-56.

[5] Pujana, J., Rivero, A., Celaya, A., \& de Lacalle, L. L. (2009). Analysis of ultrasonic-assisted drilling of Ti6A14V. International Journal of Machine Tools and Manufacture, 49(6), 500-508.

[6] Alam, K., Mitrofanov, A. V., \& Silberschmidt, V. V. (2011). Experimental investigations of forces and torque in conventional and ultrasonically-assisted drilling of cortical bone. Medical engineering \& physics, 33(2), 234-239.

[7] Makhdum, F., Jennings, L. T., Roy, A., \& Silberschmidt, V. V. (2012). Cutting forces in ultrasonically assisted drilling of carbon fibre-reinforced plastics. InJournal of Physics: Conference Series (Vol. 382, No. 1, p. 012019). IOP Publishing.

[8] Brinksmeier, E., Pecat, O., \& Rentsch, R. (2015). Quantitative analysis of chip extraction in drilling of Ti 6 Al 4 V. CIRP Annals-Manufacturing Technology,64(1), 93-96.

[9] Vakili Azghandi, B., \& Razfar, M. R. (2011). An experimental study on the effects of ultrasonic assisted drilling on chip characteristics and tool life. InAdvanced Materials Research (Vol. 325, pp. 351-356). Trans Tech Publications.

[10] Zhang, Z., \& Babitsky, V. I. (2011). Finite element modeling of a micro-drill and experiments on high speed ultrasonically assisted micro-drilling. Journal of Sound and Vibration, 330(10), 2124-2137.

[11] Chern, G. L., \& Lee, H. J. (2006). Using workpiece vibration cutting for micro-drilling. The International Journal of Advanced Manufacturing Technology, 27(7-8), 688-692.

[12] Liu, Z. F., \& Guo, T. (2014). Experimental Study on Ultrasonic Vibration Drilling of Stainless Steel 0Cr17Ni4Cu4Nb Micro-Deep-Hole. In Applied Mechanics and Materials (Vol. 692, pp. 381-386). Trans Tech Publications. 